\title{
Wnt pathway antagonists and angiogenesis
}

\author{
Bin Zhang, Jian-xing Ma ${ }^{\text {化 }}$ \\ Department of Physiology, Department of Medicine, The University of Oklahoma Health Sciences Center, Oklahoma City, Ok \\ 73104, USA \\ $\triangle$ Correspondence: jian-xing-ma@ouhsc.edu \\ Received September 19, 2010 Accepted September 27, 2010
}

\begin{abstract}
Dysregulation of the Wnt pathway has been extensively studied in multiple diseases, including some angiogenic disorders. Wnt signaling activation is a major stimulator in pathological angiogenesis and thus, Wnt antagonists are believed to have therapeutic potential for neovascular disorders. Actually, some Wnt antagonists have been identified directly from the anti-angiogenic factor family. This review summarizes the recent progress toward understanding of the roles of Wnt pathway antagonists in angiogenic regulation and their mechanism of action, and exploring their therapeutic potential.
\end{abstract}

KEYWORDS sFRPs, Dkk, WIF-1, endostatin, SERPINA3K, curcumin

\section{INTRODUCTION}

\section{The Wnt signaling pathway}

'WNT' is originated from the $\mathrm{Wg}$ (wingless) and Int genes (Rijsewijk et al., 1987). Recessive mutations in the Wg genes affect wing development in Drosophila (Sharma and Chopra, 1976). In the tumor induced by mouse mammary tumor virus, the overexpressed INT genes were identified near virus integration sites (Nusse et al., 1984). Subsequent work revealed that the Int-1 gene and the $\mathrm{Wg}$ gene were homologous and thus, named 'Wnt'.

Wnts are a family of 19 secreted, cysteine-rich glycoproteins (He et al., 2004; van Amerongen et al., 2008). Wnt ligands activate several signaling pathways involved in the regulation of development at different stages (Nusse, 2005; van Amerongen et al., 2008). The Wnt signaling cascade has two distinct branches: the canonical Wnt pathway and the non-canonical pathway (Zerlin et al., 2008). The Wnt signaling pathway is involved in multiple physiologic and pathological processes and is well studied in embryogenesis and carcinogenesis (Clevers, 2006). Recent evidence suggests that the Wnt pathway also plays an important role in angiogenesis (Masckauchán and Kitajewski, 2006).

Canonical Wnt signaling is initiated by Wnt ligands. In the absence of Wnt ligands, the transcription factor $\beta$-catenin, a down-stream effector of the canonical Wnt pathway, is phosphorylated by a protein complex containing GSK-3 in the cytosol and constantly degraded to prevent its accumulation (Li et al., 2002; Polakis, 2002). Upon binding of certain Wnt ligands to the Frizzled (Fz) receptor and the co-receptor, low-density lipoprotein receptor-related protein 5 or 6 (LRP5/6), the Fz receptor and LRP5/6 dimerize, forming a receptor/co-receptor complex (He et al., 2004). As a result, downstream signaling, including phosphorylation of LRP5/6 and stabilization of $\beta$-catenin, is initiated (Orsulic and Peifer, 1996; Dale, 1998). $\beta$-catenin is subsequently translocated into the nucleus, associates with T cell factor (TCF) for DNA binding and regulates expression of target genes (Behrens et al., 1996; He et al., 2004). Some target genes of the canonical Wnt pathway such as cyclinD1 and c-myc are implicated in cellular proliferation (He et al., 1998; Tetsu and McCormick, 1999). Recent evidence indicates that the Wnt/ $\beta$ catenin pathway also plays important roles in pathological processes, such as inflammation and angiogenesis, and also regulates inflammatory and angiogenic factors such as Cox-2 and VEGF (Howe et al., 1999; Easwaran et al., 2003; Ojesina, 2004; Tachikawa et al., 2004).

The non-canonical Wnt pathway comprises several distinct branches and is associated with some activities independent of $\mathrm{Wnt} / \mathrm{\beta}$-catenin signaling. The Wnt/PCP pathway is known to regulate orientation of cellular structure in both vertebrates (Guo et al., 2004) and invertebrates (Mlodzik, 2002). The PCP pathway is regulated by the Fz receptor, Dishevelled (Dvl), the small GTPases RhoA and Rac1, and c-jun N-terminal 
kinase (JNK) (Fanto and McNeill, 2004; Povelones et al., 2005). The relevance of PCP to vascularization is obscure. The Wnt/calcium pathway is another distinct branch of the non-canonical Wnt pathway (Kühl et al., 2000). Upon binding of certain Wnt ligands (e.g., Wnt5a and Fz2) with the Fz receptors, $G$ proteins are activated, leading to the release of intracellular calcium (Slusarski et al., 1997; Kühl et al., 2000). Furthermore, some $\mathrm{Ca}^{2+}$-sensitive enzymes such as PKC (Sheldahl et al., 1999) and $\mathrm{Ca}^{2+}$-calmodulin kinase II (Kühl et al., 2000) are activated to regulate the downstream Wnt/ calcium signaling. Although calcium signaling is known to mediate angiogenesis, the role of the $\mathrm{Wnt} /$ calcium pathway in neovascularization has not been established (Kohn et al., 1995).

There is complex crosstalk between the canonical Wnt pathway and the non-canonical pathway. Evidence suggests that non-canonical Wnt signaling antagonizes Wnt/ $\beta$-catenin signaling (Ishitani et al., 2003; Topol et al., 2003). On the other hand, Rac1 and JNK activation in the PCP pathway controls nuclear translocation of $\beta$-catenin during canonical Wnt signaling (Wu et al., 2008). The crosstalk between the Wnt signaling components and other pathways, such as the Notch pathway, the MAP kinase pathway and the NF-KB pathway, have been identified (Behrens, 2000; Nakamura et al., 2007; Umar et al., 2009). All of these angiogenesis-related pathways form a complicated net interacting with the Wnt signaling pathway.

\section{Wnt signaling pathway and angiogenesis}

Wnt signaling is essential for endothelial cell proliferation and angiogenesis. The roles of Wnt signaling in some pathological conditions with abnormal neovascularization have been revealed recently (Logan and Nusse, 2004; Masckauchán and Kitajewski, 2006). The role of Wnt signaling in vessel formation has been established based on phenotypes from disruptions and mutations in the $\mathrm{Wnt} / \mathrm{Fz}$ genes in animal models or humans. Disruption of the Wnt- 2 and Wnt-7b genes results in defects in the placental and pulmonary vasculatures in mice (Monkley et al., 1996; Shu et al., 2002). The phenotype of Fz-5 knockout mice is embryonic lethal due to the disorganization of the capillary plexus in the placenta $(\mathrm{He}$ et al., 1997). Mutations in the Fz-4 gene have been linked to FEVR, which is associated with defective retinal angiogenesis (Robitaille et al., 2002; Xu et al., 2004). Fz-4 knockout mice also show a retinal vascular defect (Robitaille et al., 2002). Taken together, these studies have established crucial roles of Wnt ligands and their receptors in angiogenesis.

The Wnt signaling pathway is also a direct mediator of endothelial cell growth and survival (Wright et al., 1999). Several Fz receptors are found on the surface of primary ECs, and these cells respond to Wnt ligands stimulation (Cheng et al., 2003; Masckauchán et al., 2005; Zerlin et al., 2008). Both of Wnt1 and Wnt5a which target the canonical and non- canonical Wnt pathways can induce EC proliferation (Masckauchán et al., 2005, 2006).

Further, Wnt signaling upregulates several pro-angiogenic factors. For example, vascular endothelial growth factor (VEGF) gene promoter region contains seven TCF/LEF binding sites (Easwaran et al., 2003). In colon cancer cells, VEGF is upregulated as a result of the ectopic activation of Wnt/ $\beta$-catenin signaling (Zhang et al., 2001; Easwaran et al., 2003). The Wnt pathway is considered a potential therapeutic target to attenuate VEGF overexpression in tumor angiogenesis (Hu et al., 2009). Interleukin-8 is another target of $\mathrm{Wnt} / \mathrm{\beta}$ catenin signaling (Masckauchán et al., 2005). IL-8 induces endothelial cell proliferation and survival. IL-8 also induces overexpression of MMP-2 and MMP-9, which both participate in the angiogenesis process (Li et al., 2003). In addition, other angiogenic factors have been reported as Wnt target genes, such as UPAR, FGF18 and 20, and MMP3 and 7 (Brabletz et al., 1999; Mann et al., 1999; Prieve and Moon, 2003; Shimokawa et al., 2003, 2005). Therefore, the angiogenic effect of $W n t / \beta$-catenin may also be through inducing proangiogenic factors.

\section{CLASSICAL, ENDOGENOUS WNT ANTAGONISTS}

\section{Secreted frizzled related proteins (sFRPs) family}

The sFRPs family consists of a group of Wnt binding proteins containing a frizzled-type cysteine-rich domain (CRD) (Rattner et al., 1997; Jones and Jomary, 2002; Kawano and Kypta, 2003). The CRD domain which contains ten cysteine residues and other conserved residues is located in the $\mathrm{N}$ terminus of the protein (Rattner et al., 1997). The $C$ terminus of sFRPs also contains a netrin (NTR) domain, containing six cysteine residues and conserved segments of hydrophobic residues (Bányai and Patthy, 1999). In mammals, there are five sFRPs, designated as SFRP1-5, with the predicted molecular weight of 33-40 kDa (around 300 amino acids) (Jones and Jomary, 2002). Since their CRD domains share sequence homology $(30 \%-50 \%)$ with CRD in the Wnt receptors $(\mathrm{Fz})$, it is predicted that SFRPs can regulate the Wnt pathway, and the function of NTR domain remains unclear (Melkonyan et al., 1997; Rattner et al., 1997; Bányai and Patthy, 1999; Jones and Jomary, 2002; Kawano and Kypta, 2003).

Based on the sequence homology, sFRPs are divided into two subgroups. One subgroup comprises sFRP1, sFRP2 and sFRP5. Another subgroup contains SFRP3 and sFRP4 (Jones and Jomary, 2002). In the sFRP family, the first identified member is sFRP3, which was originally named Frzb (Hoang et al., 1996). In the study of Xenopus embryos development, sFRP3/Frzb was reported to interact with Xwnt8 and block the Xwnt-8 signaling (Leyns et al., 1997; Wang et al., 1997a). Furthermore, in mammalian cell cultures, sFRP3/ Frzb was found to bind to Wnt-1 and inhibit the $\beta$-catenin accumulation induced by Wnt-1 (Lin et al., 1997; Wang et al., 
1997b). Since the discovery of sFRP3, other members have been identified, and some of them are identical to other existing genes. Therefore, each SFRP has several alternative names. For example, sFRP1 is also named Frp-1, SARP2 and FrzA; sFRP2 has the alternative names as SDF-5 and SARP1; sFRP3 was originally identified as Frzb, Frzb-1, Fritz and Frezzled; sFRP4 has been known as DDC-4, frpAP, frpHE and Frzb-2; sFRP5 has other names like SARP3, hFRP- $1 \mathrm{~b}$ and Frzb-1b (Jones and Jomary, 2002; Kawano and Kypta, 2003). In addition to sFRP3, sFRP1 and sFRP2 were also reported to antagonize Wnt activity (Finch et al., 1997; Xu et al., 1998; Ladher et al., 2000; Uren et al., 2000). An interesting finding from sFRP1 is that it is not always an antagonist of Wnt signaling. At low concentrations, sFRP1 act as an agonist in the tissue culture experiments, suggesting that there may be different binding sites for it (Uren et al., 2000).

The roles of sFRPs in tumor growth have been well studied (Shi et al., 2007), relating to their Wnt modulating activities. Since angiogenesis is also known to be regulated by Wnt signaling, the function of sFRPs in angiogenesis is predictable. A few studies have reported the anti-angiogenic activities of SFRPs. SFRP4 downregulates endothelial cell migration and proliferation, disrupts the stability of endothelial rings and inhibits the development of sprouts and pseudopodia. The inhibitory effects on endothelial cells are from the antagonizing effects on both the canonical Wnt pathway and the non-canonical Wnt/planar cell polarity pathway (Muley et al., 2010). In in vitro experiments, the sFRP1/FrzA mRNA level was high in the growing endothelial cells and was decreased in the confluent cells (Duplàa et al., 1999). The rate of endothelial cell proliferation was also inhibited by FrzA (Duplàa et al., 1999). However, in vivo studies of sFRP1/FrzA in angiogenesis showed conflict results. SFRP1/FrzA was found to inhibit angiogenesis in a hepatocellular carcinoma model, while inducing angiogenesis in a chick chorioallantoic membrane model (Dufourcq et al., 2002; Hu et al., 2009). The disparity may be ascribed to its concentration-dependent Wnt-regulation activities.

\section{Wnt inhibitory factor 1 (WIF-1)}

WIF-1 is another Wnt inhibitor which binds to Wnt ligands, similar to sFRPs. In 1999, it was first identified to inhibit the somitogenesis in Xenopus embryo development, and it was found to interact with Drosophila Wingless and Xenopus Wnt8 (Hsieh et al., 1999). WIF-1 does not share the CRD sequence with $\mathrm{Fz}$ or sFRPs, however, it has a highly conserved N-terminal domain named WIF domain (WD), containing 150 amino acids. WIF-1 also contains a hydrophilic domain at $C$ terminus with 45 amino acids, and five epidermal growth factor (EGF)-like repeats. The downregulated expression levels of WIF-1 were correlated with prostate, breast, lung and bladder cancers, suggesting an important role of WIF-1 in tumorigenesis (Wissmann et al., 2003).

Treatment in hepatocellular carcinoma with WIF-1 resulted in reduced microvessel density as well as the inhibition of tumor growth (Hu et al., 2009). The Wnt-regulated proangiogenic factors, such as stromal cell-derived factor-1 (SDF-1) and VEGF, were also downregulated at the same time. Further experiments demonstrated that WIF-1 significantly inhibited migration and tube formation in cultured human microvascular endothelial cells. In mouse endothelial progenitor cells (EPC), WIF-1 not only inhibited cell migration and tube formation, but also obstructed EPC differentiation and even induced EPC apoptosis (Hu et al., 2009). Therefore, the anti-angiogenic effect of WIF-1 is derived from its Wntantagonizing function and may play roles in the anti-tumor activity.

\section{Dickkopf (Dkk) family}

The human Dkk family is composed of four members, Dkk-1, 2, 3 and 4, and a unique Dkk-3-related protein which is named Soggy (Sgy). They are secreted proteins containing $\sim 250$ amino acids, except for Dkk-3 which has 350 amino acids. There are two conserved cysteine-rich domains (Cys- 1 and Cys-2) in Dkks, containing 10 cysteine residues in each position (Krupnik et al., 1999). However, Dkk-3 related Sgy lacks cysteine-rich domains (Krupnik et al., 1999). In the Xenopus embryo development assay, Dkk-1 and Dkk-4 inhibit the Wnt-induced secondary axis formation, while Dkk-2, Dkk-3 and Sgy lack this activity (Krupnik et al., 1999; Mao and Niehrs, 2003).

In the Dkk family, Dkk-1 is the most studied member. It was first identified to be a secreted inducer of Spemann's organizer in Xenopus embryo in 1998 (Glinka et al., 1998). Dkk-1 is essential for head formation and also a potent Wnt signaling antagonist. Dkk-1 inhibited the effect of Xwnt-8 in Xenopus embryo, but did not block Dishevelled (Dvl/Ssh)induced secondary axis formation, suggesting a potential upstream target in the Wnt signaling pathway (Glinka et al., 1998). The binding partner of Dkk-1 was not identified until 2001. Two groups established the receptor for Dkk-1 almost at the same time, which are LRP5/6, the co-receptors of Wnt proteins (Mao et al., 2001; Semënov et al., 2001). The binding of Dkk-1 to LRP5/6 results in the blockage of Fz-LRP association and subsequently, specific inhibition of the Wnt/ $\beta$-catenin pathway (Semënov et al., 2001). In addition to LRP5/6, Kremen1 (Krm1) and Kremen2 (Krm2) are also the high-affinity receptors for Dkk-1 and can cooperate with Dkk-1 to inhibit Wnt signaling (Mao et al., 2002). Krm2, Dkk-1 and LRP6 have been reported to form a ternary complex and induce rapid endocytosis and removal of the Wnt receptor LRP6 from the plasma membrane (Mao et al., 2002). In Dkk1 , the $\mathrm{C}$-terminal fragment containing the Cys-2 domain binds to LRP6 and Krm and further inhibits the Wnt signaling 
activation as shown by the Xenopus embryo secondary axis induction and the LEF-1 luciferase reporter assays (Brott and Sokol, 2002; Li et al., 2002; Mao and Niehrs, 2003). It suggests that the C-terminal domain of Dkks is more important for Wnt/LRP6 regulation. However, whether Dkk-1 can induce LRP6 internalization is still controversial. In 2008, a group reported that Dkk-1 and Wnt-3a induced internalization of LRP6 through distinct pathways (Yamamoto et al., 2008). At the same time, another group reported that Dkk-1 blocked Wnt signaling but did not promote LRP6 internalization and degradation (Semënov et al., 2008). Therefore, the mechanism for the antagonizing effect of Dkk-1 on LRP6 and $W n t / \beta-C a t e n i n$ pathway remains unclear.

Dkk-4 has displayed the Wnt antagonist activity similar to Dkk-1 (Krupnik et al., 1999). However, the binding between Dkk-4 and LRP6 has not been demonstrated. Dkk-3 has no inhibitory effect on Wnt signaling and does not bind to LRPs or Krm1/2 (Krupnik et al., 1999; Mao et al., 2001, 2002; Mao and Niehrs, 2003). Dkk-2 binds to LRP6 with a lower affinity and the binding $\mathrm{Kd}$ value is approximately 2 folds of that for Dkk-1 (0.73 nM vs $0.34 \mathrm{nM}$ ) (Mao et al., 2001). This may be one of the reasons explaining why Dkk-2 shows conflicting functions in the Xwnt8-induced axis duplication by different groups. Two groups reported that Dkk-2 is a poor inhibitor of Wnt signaling (Krupnik et al., 1999; Wu et al., 2000), while another group reported the Wnt antagonizing activity of Dkk-2 (Brott and Sokol, 2002). This disparity may be ascribed to different expression levels of Dkk-2 in their experiments. The Wnt antagonist activity of Dkk-2 is from C-terminal domain involving Cys-2, same as Dkk-1 (Brott and Sokol, 2002; Li et al., 2002; Mao and Niehrs, 2003). However, the N-terminal domains in Dkk-1 and Dkk-2 have different functions. The Nterminal fragment of Dkk-2 synergies with LRP6 to induce Wnt signaling activation (Brott and Sokol, 2002), but the Nterminal domain of Dkk-1 has no such function. Together with other evidence, Dkk-2 is suggested to play the role as an agonist in low-Wnt/high-LRP6 condition, and acts as an antagonist in environment with high-Wnt levels (Wu et al., 2000; Mao et al., 2001; Brott and Sokol, 2002; Li et al., 2002; Mao et al., 2002; Mao and Niehrs, 2003).

As a Wnt-mediated event, angiogenesis is predicted to be regulated by Wnt-antagonizing Dkks, especially Dkk-1, which is the most studied and potent family member. The ameliorative effect of Dkk-1 has been found in the ocular pathological neovascularization with ectopically higher activation level of Wnt signaling in the eye (Chen et al., 2007). In the eyecups of the very low-density lipoprotein receptor (VLDLR) gene knockout $\left(\mathrm{Vldll}^{-1-}\right)$ mice, expression levels of Wnt co-receptor LRP5/6 were significantly upregulated, concomitant with accumulation of $\beta$-catenin, suggesting an over activation of the Wnt pathway. Knockdown of VLDLR in cultured endothelial cells by siRNA also upregulated LRP5/6 expression and stabilized $\beta$-catenin. Consistent with the role of Wnt signaling in angiogenesis, subretinal neovascularization develops in $\mathrm{VIdlr}^{-1-}$ mice. This phenotype presents similarly to the neovasculazation in patients with wet AMD. This subretinal neovascularization correlates with overexpression of VEGF in $\mathrm{VIdll}^{-1-}$ mice. In this abnormal Wnt-induced angiogenic model, Dkk-1 effectively decreased VEGF and $\beta$-catenin levels in the RPE of $\mathrm{VIdll}^{-1-}$ mice and in cultured cells with VLDLR knockdown (Chen et al., 2007). Recently, another study found that the Wnt pathway is over activated in the retinas of the OIR mouse model, correlating with retinal neovascularization. Further, Dkk-1 also effectively attenuated retinal neovascularization as well as Wnt signaling (Chen et al., 2009). These mouse studies provide new evidence to support the anti-angiogenic role of Dkk-1 in ocular angiogenesis.

\section{ANTI-ANGIOGENIC FACTORS AS WNT ANTAGONISTS}

Some Wnts act as pro-angiogenic factors and some Wnt antagonists play anti-angiogenic roles. Furthermore, several endogenous anti-angiogenic factors have also been reported to inhibit Wnt signaling activity, such as endostatin and SERPINA3K, possible new mechanisms for anti-angiogenic functions of these factors.

\section{Endostatin}

Endostatin is a C-terminal fragment of collagen XVIII and has been identified to be an anti-angiogenic factor (O'Reilly et al., 1997; Hanai et al., 2002). It is a $20 \mathrm{kDa}$ peptide which can inhibit endothelial cell proliferation and tumor growth (O'Reilly et al., 1997). Endostatin is involved in many aspects of embryo development. In a Xenopus embryo developmental study, endostatin overexpression blocked the Xenopus axis duplication induced by $\beta$-catenin, indicating an inhibitory effect of endostatin on the Wnt signaling pathway (Hanai et al., 2002). Endostatin inhibited $\beta$-catenin-induced TCF/LEF transcription activity, but failed to inhibit the effect of TCF-VP16 (a constitutive downstream activator, independent of $\beta$-catenin) (Hanai et al., 2002). At the same time, suppression of endothelial cell migration and inhibition of the cell cycle by endostatin were reversed by TCF-VP16 (Hanai et al., 2002). It suggested that the potential target for endostatin was at the upstream of TCF, but not earlier than $\beta$ catenin. Actually, endostatin can degrade both normal and "stabilized" (no N-terminal phosphorylation sites) forms of $\beta$ catenin, revealing a GSK3-independent $\beta$-catenin-degradation signaling pathway (Hanai et al., 2002). This mechanism of endostatin is distinct from other secreted Wnt-antagonists that act at the Wnt ligand/receptor level. This novel finding also suggests that the anti-angiogenic activity of endostatin may act through inhibition of TCF-dependent, canonical Wntmediated transcription. 


\section{SERPINA3K}

SERPINA3K was first identified as a specific inhibitor of tissue kallikrein and thus named kallikrein binding protein (Chao et al., 1986, 1990). Amino acid sequence analysis classified SERPINA3K into the serine proteinase inhibitor (serpin) family (Gettins, 2002). Tissue kallikrein is a serine proteinase and releases bioactive kinins from kininogens (Clements, 1989; Murray et al., 1990). SERPINA3K specifically binds to tissue kallikrein, forming a covalent complex and inhibits proteolytic activities of tissue kallikrein (Chao et al., 1990; Ma et al., 1995). Later studies suggest that SERPINA3K has functions in addition to the inhibition of tissue kallikrein. SERPINA3K has been found to inhibit angiogenesis and to reduce vascular permeability (Miao et al., 2002; Gao et al., 2003). These anti-angiogenic effects of SERPINA3K have been shown to be independent of its interactions with the kallikrein-kinin system (Gao et al., 2003; Zhang et al., 2008).

As an angiogenic inhibitor, SERPINA3K was found to downregulate several pro-angiogenic cytokines such as CTGF and VEGF, which are also target genes of the Wnt pathway (Zhang et al., 2009, 2010a, b). In experimental diabetic models, SERPINA3K blocked Wnt signaling activation in the retinas with microvascular complications and in cells treated with high glucose, suggesting that SERPINA3K may regulate angiogenesis through interacting with the Wnt pathway (Zhang et al., 2010a, b). Further, SERPINA3K was identified as a Wnt antagonist since it blocked the Wnt ligandinduced Wnt pathway activation, blocking phosphorylation of LRP6, cytosolic $\beta$-catenin stabilization, TCF/LEF-mediated transcription activity and Xenopus axis duplication. Coprecipitation and ligand binding assay showed that SERPINA3K binds to LRP6 with a Kd of $10 \mathrm{nM}$. Under the same conditions, SERPINA3K did not bind to the Fz receptor or low-density lipoprotein receptor. The interaction between SERPINA3K and the extracellular domain of LRP6 blocked Fz/LRP6 (receptor/co-receptor) dimerization induced by a Wnt ligand. Together with the pro-angiogenic role of Wnt signaling, this study suggests that the antagonizing activity of SERPINA3K to LRP6 is responsible, at least in part, for its anti-angiogenic activities.

\section{THE WNT PATHWAY OFFERS MULTIPLE TARGETS FOR THERAPEUTIC COMPOUNDS}

Since Wnt signaling displays potent angiogenic activities, components of the Wnt pathway have been considered promising drug targets for the treatment of neovascular disorders. In addition to the natural Wnt antagonist proteins, more and more small compounds have been developed to inhibit the Wnt pathway through various pathway targets (Rey and Ellies). One of the advantages of the drugs blocking the $W n t / \beta$-catenin pathway is their potential to target multiple potential factors. The agonists and antagonists of the Wnt receptor/co-receptor can be used to regulate Wnt signaling from the extracellular side. Small molecular compounds can be designed to target the intracellular components of the Wnt pathway, such as $\beta$-catenin, some proteases and axin1. The phosphorylation sites on LRP6, DVL, GSK3 and the relative kinase activities all represent potential drug targets. Drugs can also be designed to regulate nuclear translocation and nuclear protein binding activity of $\beta$-catenin. Recently, JNK and AKT were found to phosphorylate $\beta$-catenin and enhance $\beta$-catenin nuclear translocation (Wu et al., 2008). Therefore, the inhibitors targeting JNK and AKT can potentially inhibit the canonical Wnt pathway.

\section{Curcumin}

Curcumin is a small compound isolated from the spice turmeric, and it is a member in the ginger family. Curcumin was shown to inhibit cancer (Conney et al., 1991; Huang et al., 1994), and was later reported to function as an angiogenic inhibitor (Arbiser et al., 1998). Since this report, the antiangiogenic effect of curcumin and its potential mechanism of action have been studied extensively in different models and organs (Adams et al., 2004; Furness et al., 2005; Bhandarkar and Arbiser, 2007; Kunnumakkara et al., 2008; Varinska et al., 2010). Several signaling transduction pathways have been found to be regulated by curcumin, including protein kinase $C$, NF-kappaB and AP-1 (Bhandarkar and Arbiser, 2007). Recently, curcumin has been identified to be an inhibitor of the $\mathrm{Wnt} / \beta$-catenin pathway. It can induce $\beta$-catenin degradation via increasing caspase activity, and further plays antiangiogenic roles (Park et al., 2005; Leow et al., 2009). Another group reported that the natural derivatives of curcumin also inhibited the $\mathrm{Wnt} / \beta$-catenin pathway, but it is through downregulation of $\mathrm{p} 300$, one of the transcriptional coactivators (Ryu et al., 2008). These studies suggest that the Wnt-antagonizing activity of curcumin can contribute to its anti-cancer and anti-angiogenesis effects.

\section{SUMMARY}

Most of the classical Wnt antagonists were first identified from Xenopus embryo, and their functions were only known in development. Recently, more and more Wnt antagonists have been reported from other protein families, such as the antiangiogenic factor family, directly implying the Wnt pathway in pathogenesis of angiogenic disorders. At the same time, classical Wnt antagonists have also been found to inhibit angiogenesis, suggesting the potential application of the Wnt antagonists in anti-angiogenic therapies. Small molecule compounds have the advantages in the high-throughput screening and drug delivery. There are multiple drug targets in the Wnt pathway for compound design, which may represent a major effort in the future drug development to treat angiogenic disorders. 


\section{REFERENCES}

Adams, B.K., Ferstl, E.M., Davis, M.C., Herold, M., Kurtkaya, S., Camalier, R.F., Hollingshead, M.G., Kaur, G., Sausville, E.A., Rickles, F.R., et al. (2004). Synthesis and biological evaluation of novel curcumin analogs as anti-cancer and anti-angiogenesis agents. Bioorg Med Chem 12, 3871-3883.

Arbiser, J.L., Klauber, N., Rohan, R., van Leeuwen, R., Huang, M.T., Fisher, C., Flynn, E., and Byers, H.R. (1998). Curcumin is an in vivo inhibitor of angiogenesis. Mol Med 4, 376-383.

Bányai, L., and Patthy, L. (1999). The NTR module: domains of netrins, secreted frizzled related proteins, and type I procollagen Cproteinase enhancer protein are homologous with tissue inhibitors of metalloproteases. Protein Sci 8, 1636-1642.

Behrens, J. (2000). Cross-regulation of the Wnt signalling pathway: a role of MAP kinases. J Cell Sci 113, 911-919.

Behrens, J., von Kries, J.P., Kühl, M., Bruhn, L., Wedlich, D., Grosschedl, R., and Birchmeier, W. (1996). Functional interaction of beta-catenin with the transcription factor LEF-1. Nature 382, 638-642.

Bhandarkar, S.S., and Arbiser, J.L. (2007). Curcumin as an inhibitor of angiogenesis. Adv Exp Med Biol 595, 185-195.

Brabletz, T., Jung, A., Dag, S., Hlubek, F., and Kirchner, T. (1999). beta-catenin regulates the expression of the matrix metalloproteinase-7 in human colorectal cancer. Am J Pathol 155, 1033-1038.

Brott, B.K., and Sokol, S.Y. (2002). Regulation of Wnt/LRP signaling by distinct domains of Dickkopf proteins. Mol Cell Biol 22, 6100-6110.

Chamorro, M.N., Schwartz, D.R., Vonica, A., Brivanlou, A.H., Cho, K. R., and Varmus, H.E. (2005). FGF-20 and DKK1 are transcriptional targets of beta-catenin and FGF-20 is implicated in cancer and development. EMBO J 24, 73-84.

Chao, J., Chai, K.X., Chen, L.M., Xiong, W., Chao, S., Woodley-Miller, C., Wang, L.X., Lu, H.S., and Chao, L. (1990). Tissue kallikreinbinding protein is a serpin. I. Purification, characterization, and distribution in normotensive and spontaneously hypertensive rats. J Biol Chem 265, 16394-16401.

Chao, J., Tillman, D.M., Wang, M.Y., Margolius, H.S., and Chao, L. (1986). Identification of a new tissue-kallikrein-binding protein. Biochem J 239, 325-331.

Chen, Y., Hu, Y., Lu, K., Flannery, J.G., and Ma, J.X. (2007). Very low density lipoprotein receptor, a negative regulator of the wnt signaling pathway and choroidal neovascularization. J Biol Chem 282, 34420-34428.

Chen, Y., Hu, Y., Zhou, T., Zhou, K.K., Mott, R., Wu, M., Boulton, M., Lyons, T.J., Gao, G., and Ma, J.X. (2009). Activation of the Wnt pathway plays a pathogenic role in diabetic retinopathy in humans and animal models. Am J Pathol 175, 2676-2685.

Cheng, C.W., Smith, S.K., and Charnock-Jones, D.S. (2003). Wnt-1 signaling inhibits human umbilical vein endothelial cell proliferation and alters cell morphology. Exp Cell Res 291, 415-425.

Clements, J.A. (1989). The glandular kallikrein family of enzymes: tissue-specific expression and hormonal regulation. Endocr Rev 10, 393-419.

Clevers, H. (2006). Wnt/beta-catenin signaling in development and disease. Cell 127, 469-480.
Conney, A.H., Lysz, T., Ferraro, T., Abidi, T.F., Manchand, P.S., Laskin, J.D., and Huang, M.T. (1991). Inhibitory effect of curcumin and some related dietary compounds on tumor promotion and arachidonic acid metabolism in mouse skin. Adv Enzyme Regul 31, 385-396.

Dale, T.C. (1998). Signal transduction by the Wnt family of ligands. Biochem J 329, 209-223.

Dufourcq, P., Couffinhal, T., Ezan, J., Barandon, L., Moreau, C., Daret, D., and Duplàa, C. (2002). FrzA, a secreted frizzled related protein, induced angiogenic response. Circulation 106, 3097-3103.

Duplàa, C., Jaspard, B., Moreau, C., and D'Amore, P.A. (1999). Identification and cloning of a secreted protein related to the cysteine-rich domain of frizzled. Evidence for a role in endothelial cell growth control. Circ Res 84, 1433-1445.

Easwaran, V., Lee, S.H., Inge, L., Guo, L., Goldbeck, C., Garrett, E., Wiesmann, M., Garcia, P.D., Fuller, J.H., Chan, V., et al. (2003). beta-Catenin regulates vascular endothelial growth factor expression in colon cancer. Cancer Res 63, 3145-3153.

Fanto, M., and McNeill, H. (2004). Planar polarity from flies to vertebrates. J Cell Sci 117, 527-533.

Finch, P.W., He, X., Kelley, M.J., Uren, A., Schaudies, R.P., Popescu, N.C., Rudikoff, S., Aaronson, S.A., Varmus, H.E., and Rubin, J.S. (1997). Purification and molecular cloning of a secreted, Frizzledrelated antagonist of Wnt action. Proc Natl Acad Sci U S A 94, 6770-6775.

Furness, M.S., Robinson, T.P., Ehlers, T., Hubbard, R.B. 4th, Arbiser, J.L., Goldsmith, D.J., and Bowen, J.P. (2005). Antiangiogenic agents: studies on fumagillin and curcumin analogs. Curr Pharm Des 11, 357-373.

Gao, G., Shao, C., Zhang, S.X., Dudley, A., Fant, J., and Ma, J.X. (2003). Kallikrein-binding protein inhibits retinal neovascularization and decreases vascular leakage. Diabetologia 46, 689-698.

Gettins, P.G. (2002). Serpin structure, mechanism, and function. Chem Rev 102, 4751-4804.

Glinka, A., Wu, W., Delius, H., Monaghan, A.P., Blumenstock, C., and Niehrs, C. (1998). Dickkopf-1 is a member of a new family of secreted proteins and functions in head induction. Nature 391, 357-362.

Guo, N., Hawkins, C., and Nathans, J. (2004). Frizzled6 controls hair patterning in mice. Proc Natl Acad Sci U S A 101, 9277-9281.

Hanai, J., Gloy, J., Karumanchi, S.A., Kale, S., Tang, J., Hu, G., Chan, B., Ramchandran, R., Jha, V., Sukhatme, V.P., et al. (2002). Endostatin is a potential inhibitor of Wnt signaling. J Cell Biol 158, 529-539.

He, T.C., Sparks, A.B., Rago, C., Hermeking, H., Zawel, L., da Costa, L.T., Morin, P.J., Vogelstein, B., and Kinzler, K.W. (1998). Identification of C-MYC as a target of the APC pathway. Science 281, 1509-1512.

He, X., Saint-Jeannet, J.P., Wang, Y., Nathans, J., Dawid, I., and Varmus, H. (1997). A member of the Frizzled protein family mediating axis induction by Wnt-5A. Science 275, 1652-1654.

He, X., Semenov, M., Tamai, K., and Zeng, X. (2004). LDL receptorrelated proteins 5 and 6 in Wnt/beta-catenin signaling: arrows point the way. Development131, 1663-1677.

Hoang, B., Moos, M. Jr, Vukicevic, S., and Luyten, F.P. (1996). Primary structure and tissue distribution of FRZB, a novel protein related to Drosophila frizzled, suggest a role in skeletal morpho- 
genesis. J Biol Chem 271, 26131-26137.

Howe, L.R., Subbaramaiah, K., Chung, W.J., Dannenberg, A.J., and Brown, A.M. (1999). Transcriptional activation of cyclooxygenase2 in Wnt-1-transformed mouse mammary epithelial cells. Cancer Res 59, 1572-1577.

Hsieh, J.C., Kodjabachian, L., Rebbert, M.L., Rattner, A., Smallwood, P.M., Samos, C.H., Nusse, R., Dawid, I.B., and Nathans, J. (1999). A new secreted protein that binds to Wnt proteins and inhibits their activities. Nature 398, 431-436.

Hu, J., Dong, A., Fernandez-Ruiz, V., Shan, J., Kawa, M., MartínezAnsó, E., Prieto, J., and Qian, C. (2009). Blockade of Wnt signaling inhibits angiogenesis and tumor growth in hepatocellular carcinoma. Cancer Res 69, 6951-6959.

Huang, M.T., Lou, Y.R., Ma, W., Newmark, H.L., Reuhl, K.R., and Conney, A.H. (1994). Inhibitory effects of dietary curcumin on forestomach, duodenal, and colon carcinogenesis in mice. Cancer Res 54, 5841-5847.

Ishitani, T., Kishida, S., Hyodo-Miura, J., Ueno, N., Yasuda, J., Waterman, M., Shibuya, H., Moon, R.T., Ninomiya-Tsuji, J., and Matsumoto, K. (2003). The TAK1-NLK mitogen-activated protein kinase cascade functions in the $\mathrm{Wnt}-5 \mathrm{a} / \mathrm{Ca}(2+)$ pathway to antagonize Wnt/beta-catenin signaling. Mol Cell Biol 23, 131-139.

Jones, S.E., and Jomary, C. (2002). Secreted Frizzled-related proteins: searching for relationships and patterns. Bioessays 24 , 811-820.

Kawano, Y., and Kypta, R. (2003). Secreted antagonists of the Wnt signalling pathway. J Cell Sci 116, 2627-2634.

Kohn, E.C., Alessandro, R., Spoonster, J., Wersto, R.P., and Liotta, L. A. (1995). Angiogenesis: role of calcium-mediated signal transduction. Proc Natl Acad Sci U S A 92, 1307-1311.

Krupnik, V.E., Sharp, J.D., Jiang, C., Robison, K., Chickering, T.W., Amaravadi, L., Brown, D.E., Guyot, D., Mays, G., Leiby, K., et al. (1999). Functional and structural diversity of the human Dickkopf gene family. Gene 238, 301-313.

Kühl, M., Sheldahl, L.C., Malbon, C.C., and Moon, R.T. (2000). $\mathrm{Ca}(2+) /$ calmodulin-dependent protein kinase II is stimulated by Wnt and Frizzled homologs and promotes ventral cell fates in Xenopus. J Biol Chem 275, 12701-12711.

Kühl, M., Sheldahl, L.C., Park, M., Miller, J.R., and Moon, R.T. (2000). The $\mathrm{Wnt} / \mathrm{Ca}^{2+}$ pathway: a new vertebrate Wnt signaling pathway takes shape. Trends Genet 16, 279-283.

Kunnumakkara, A.B., Anand, P., and Aggarwal, B.B. (2008). Curcumin inhibits proliferation, invasion, angiogenesis and metastasis of different cancers through interaction with multiple cell signaling proteins. Cancer Lett 269, 199-225.

Ladher, R.K., Church, V.L., Allen, S., Robson, L., Abdelfattah, A., Brown, N.A., Hattersley, G., Rosen, V., Luyten, F.P., Dale, L., et al. (2000). Cloning and expression of the Wnt antagonists Sfrp-2 and Frzb during chick development. Dev Biol 218, 183-198.

Leow, P.C., Tian, Q., Ong, Z.Y., Yang, Z., and Ee, P.L. (2009). Antitumor activity of natural compounds, curcumin and PKF118-310, as Wnt/beta-catenin antagonists against human osteosarcoma cells. Invest New Drugs. In press.

Leyns, L., Bouwmeester, T., Kim, S.H., Piccolo, S., and De Robertis, E.M. (1997). Frzb-1 is a secreted antagonist of Wnt signaling expressed in the Spemann organizer. Cell 88, 747-756.

Li, A., Dubey, S., Varney, M.L., Dave, B.J., and Singh, R.K. (2003). IL8 directly enhanced endothelial cell survival, proliferation, and matrix metalloproteinases production and regulated angiogenesis. J Immunol 170, 3369-3376.

Li, L., Mao, J., Sun, L., Liu, W., and Wu, D. (2002). Second cysteinerich domain of Dickkopf-2 activates canonical Wnt signaling pathway via LRP-6 independently of dishevelled. J Biol Chem 277, 5977-5981.

Lin, K., Wang, S., Julius, M.A., Kitajewski, J., Moos, M. Jr, and Luyten, F.P. (1997). The cysteine-rich frizzled domain of Frzb-1 is required and sufficient for modulation of Wnt signaling. Proc Natl Acad Sci U S A 94, 11196-11200.

Logan, C.Y., and Nusse, R. (2004). The Wnt signaling pathway in development and disease. Annu Rev Cell Dev Biol 20, 781-810.

Ma, J.X., Yang, Z., Chao, J., and Chao, L. (1995). Intramuscular delivery of rat kallikrein-binding protein gene reverses hypotension in transgenic mice expressing human tissue kallikrein. J Biol Chem 270, 451-455.

Mann, B., Gelos, M., Siedow, A., Hanski, M.L., Gratchev, A., llyas, M., Bodmer, W.F., Moyer, M.P., Riecken, E.O., Buhr, H.J., et al. (1999). Target genes of beta-catenin-T cell-factor/lymphoid-enhancerfactor signaling in human colorectal carcinomas. Proc Natl Acad Sci U S A 96, 1603-1608.

Mao, B., and Niehrs, C. (2003). Kremen2 modulates Dickkopf2 activity during Wnt/LRP6 signaling. Gene 302, 179-183.

Mao, B., Wu, W., Davidson, G., Marhold, J., Li, M., Mechler, B.M., Delius, H., Hoppe, D., Stannek, P., Walter, C., et al. (2002). Kremen proteins are Dickkopf receptors that regulate Wnt/beta-catenin signalling. Nature 417, 664-667.

Mao, B., Wu, W., Li, Y., Hoppe, D., Stannek, P., Glinka, A., and Niehrs, C. (2001). LDL-receptor-related protein 6 is a receptor for Dickkopf proteins. Nature 411, 321-325.

Masckauchán, T.N., Agalliu, D., Vorontchikhina, M., Ahn, A., Parmalee, N.L., Li, C.M., Khoo, A., Tycko, B., Brown, A.M., and Kitajewski, J. (2006). Wnt5a signaling induces proliferation and survival of endothelial cells in vitro and expression of MMP-1 and Tie-2. Mol Biol Cell 17, 5163-5172.

Masckauchán, T.N., and Kitajewski, J. (2006). Wnt/Frizzled signaling in the vasculature: new angiogenic factors in sight. Physiology (Bethesda) 21, 181-188.

Masckauchán, T.N., Shawber, C.J., Funahashi, Y., Li, C.M., and Kitajewski, J. (2005). Wnt/beta-catenin signaling induces proliferation, survival and interleukin-8 in human endothelial cells. Angiogenesis 8, 43-51.

Melkonyan, H.S., Chang, W.C., Shapiro, J.P., Mahadevappa, M., Fitzpatrick, P.A., Kiefer, M.C., Tomei, L.D., and Umansky, S.R. (1997). SARPs: a family of secreted apoptosis-related proteins. Proc Natl Acad Sci U S A 94, 13636-13641.

Miao, R.Q., Agata, J., Chao, L., and Chao, J. (2002). Kallistatin is a new inhibitor of angiogenesis and tumor growth. Blood 100, 3245-3252.

Mlodzik, M. (2002). Planar cell polarization: do the same mechanisms regulate Drosophila tissue polarity and vertebrate gastrulation? Trends Genet 18, 564-571.

Monkley, S.J., Delaney, S.J., Pennisi, D.J., Christiansen, J.H., and Wainwright, B.J. (1996). Targeted disruption of the Wnt2 gene results in placentation defects. Development 122, 3343-3353.

Muley, A., Majumder, S., Kolluru, G.K., Parkinson, S., Viola, H., Hool, L., Arfuso, F., Ganss, R., Dharmarajan, A., and Chatterjee, S. (2010). Secreted frizzled-related protein 4: an angiogenesis 
inhibitor. Am J Pathol 176, 1505-1516.

Murray, S.R., Chao, J., Lin, F.K., and Chao, L. (1990). Kallikrein multigene families and the regulation of their expression. $J$ Cardiovasc Pharmacol 15, S7-S16.

Nakamura, T., Tsuchiya, K., and Watanabe, M. (2007). Crosstalk between Wnt and Notch signaling in intestinal epithelial cell fate decision. J Gastroenterol 42, 705-710.

Nusse, R. (2005). Wnt signaling in disease and in development. Cell Res 15, 28-32.

Nusse, R., van Ooyen, A., Cox, D., Fung, Y.K., and Varmus, H. (1984). Mode of proviral activation of a putative mammary oncogene (int-1) on mouse chromosome 15. Nature 307, 131-136.

O'Reilly, M.S., Boehm, T., Shing, Y., Fukai, N., Vasios, G., Lane, W.S., Flynn, E., Birkhead, J.R., Olsen, B.R., and Folkman, J. (1997). Endostatin: an endogenous inhibitor of angiogenesis and tumor growth. Cell 88, 277-285.

Ojesina, A.I. (2004). The role of beta-catenin in regulating angiogenesis in Wilms tumor. J Pediatr Surg 39, 1446-1447.

Orsulic, S., and Peifer, M. (1996). Cell-cell signalling: Wingless lands at last. Curr Biol 6, 1363-1367.

Park, C.H., Hahm, E.R., Park, S., Kim, H.K., and Yang, C.H. (2005). The inhibitory mechanism of curcumin and its derivative against beta-catenin/Tcf signaling. FEBS Lett 579, 2965-2971.

Polakis, P. (2002). Casein kinase 1: a Wnt'er of disconnect. Curr Biol 12, R499-R501.

Povelones, M., Howes, R., Fish, M., and Nusse, R. (2005). Genetic evidence that Drosophila frizzled controls planar cell polarity and Armadillo signaling by a common mechanism. Genetics 171 , 1643-1654.

Prieve, M.G., and Moon, R.T. (2003). Stromelysin-1 and mesothelin are differentially regulated by Wnt-5a and Wnt-1 in C57mg mouse mammary epithelial cells. BMC Dev Biol 3, 2.

Rattner, A., Hsieh, J.C., Smallwood, P.M., Gilbert, D.J., Copeland, N. G., Jenkins, N.A., and Nathans, J. (1997). A family of secreted proteins contains homology to the cysteine-rich ligand-binding domain of frizzled receptors. Proc Natl Acad Sci U S A 94, 2859-2863.

Rey, J.P., and Ellies, D.L. (2010). Wnt modulators in the biotech pipeline. Dev Dyn 239, 102-114.

Rijsewijk, F., Schuermann, M., Wagenaar, E., Parren, P., Weigel, D., and Nusse, R. (1987). The Drosophila homolog of the mouse mammary oncogene int-1 is identical to the segment polarity gene wingless. Cell 50, 649-657.

Robitaille, J., MacDonald, M.L., Kaykas, A., Sheldahl, L.C., Zeisler, J., Dubé, M.P., Zhang, L.H., Singaraja, R.R., Guernsey, D.L., Zheng, B., et al. (2002). Mutant frizzled-4 disrupts retinal angiogenesis in familial exudative vitreoretinopathy. Nat Genet 32, 326-330.

Ryu, M.J., Cho, M., Song, J.Y., Yun, Y.S., Choi, I.W., Kim, D.E., Park, B.S., and Oh, S. (2008). Natural derivatives of curcumin attenuate the $\mathrm{Wnt} /$ beta-catenin pathway through down-regulation of the transcriptional coactivator p300. Biochem Biophys Res Commun 377, 1304-1308.

Semënov, M.V., Tamai, K., Brott, B.K., Kühl, M., Sokol, S., and He, X. (2001). Head inducer Dickkopf-1 is a ligand for Wnt coreceptor LRP6. Curr Biol 11, 951-961.

Semënov, M.V., Zhang, X., and He, X. (2008). DKK1 antagonizes Wnt signaling without promotion of LRP6 internalization and degradation. J Biol Chem 283, 21427-21432.
Sharma, R.P., and Chopra, V.L. (1976). Effect of the Wingless (wg1) mutation on wing and haltere development in Drosophila melanogaster. Dev Biol 48, 461-465.

Sheldahl, L.C., Park, M., Malbon, C.C., and Moon, R.T. (1999). Protein kinase $C$ is differentially stimulated by Wnt and Frizzled homologs in a G-protein-dependent manner. Curr Biol 9, 695-698.

Shi, Y., He, B., You, L., and Jablons, D.M. (2007). Roles of secreted frizzled-related proteins in cancer. Acta Pharmacol Sin 28, 1499-1504.

Shimokawa, T., Furukawa, Y., Sakai, M., Li, M., Miwa, N., Lin, Y.M., and Nakamura, Y. (2003). Involvement of the FGF18 gene in colorectal carcinogenesis, as a novel downstream target of the beta-catenin/T-cell factor complex. Cancer Res 63, 6116-6120.

Shu, W., Jiang, Y.Q., Lu, M.M., and Morrisey, E.E. (2002). Wnt7b regulates mesenchymal proliferation and vascular development in the lung. Development 129, 4831-4842.

Slusarski, D.C., Corces, V.G., and Moon, R.T. (1997). Interaction of Wnt and a Frizzled homologue triggers G-protein-linked phosphatidylinositol signalling. Nature 390, 410-413.

Tachikawa, K., Schröder, O., Frey, G., Briggs, S.P., and Sera, T. (2004). Regulation of the endogenous VEGF-A gene by exogenous designed regulatory proteins. Proc Natl Acad Sci U S A 101, 15225-15230.

Tetsu, O., and McCormick, F. (1999). Beta-catenin regulates expression of cyclin D1 in colon carcinoma cells. Nature 398, $422-426$.

Topol, L., Jiang, X., Choi, H., Garrett-Beal, L., Carolan, P.J., and Yang, Y. (2003). Wnt-5a inhibits the canonical Wnt pathway by promoting GSK-3-independent beta-catenin degradation. J Cell Biol 162, 899-908.

Umar, S., Sarkar, S., Wang, Y., and Singh, P. (2009). Functional cross-talk between beta-catenin and NFkappaB signaling pathways in colonic crypts of mice in response to progastrin. $\mathrm{J}$ Biol Chem 284, 22274-22284.

Uren, A., Reichsman, F., Anest, V., Taylor, W.G., Muraiso, K., Bottaro, D.P., Cumberledge, S., and Rubin, J.S. (2000). Secreted frizzledrelated protein-1 binds directly to Wingless and is a biphasic modulator of Wnt signaling. J Biol Chem 275, 4374-4382.

van Amerongen, R., Mikels, A., and Nusse, R. (2008). Alternative wnt signaling is initiated by distinct receptors. Sci Signal 1, re9.

Varinska, L., Mirossay, L., Mojzisova, G., and Mojzis, J. (2010). Antiangogenic effect of selected phytochemicals. Pharmazie 65, 57-63.

Wang, S., Krinks, M., Lin, K., Luyten, F.P., and Moos, M. Jr. (1997a). Frzb, a secreted protein expressed in the Spemann organizer, binds and inhibits Wnt-8. Cell 88, 757-766.

Wang, S., Krinks, M., and Moos, M. Jr. (1997b). Frzb-1, an antagonist of Wnt-1 and Wnt-8, does not block signaling by Wnts $-3 A$, $-5 A$, or -11. Biochem Biophys Res Commun 236, 502-504.

Wissmann, C., Wild, P.J., Kaiser, S., Roepcke, S., Stoehr, R., Woenckhaus, M., Kristiansen, G., Hsieh, J.C., Hofstaedter, F., Hartmann, A., et al. (2003). WIF1, a component of the Wnt pathway, is down-regulated in prostate, breast, lung, and bladder cancer. J Pathol 201, 204-212.

Wright, M., Aikawa, M., Szeto, W., and Papkoff, J. (1999). Identification of a Wnt-responsive signal transduction pathway in primary endothelial cells. Biochem Biophys Res Commun 263, 384-388.

Wu, W., Glinka, A., Delius, H., and Niehrs, C. (2000). Mutual 
antagonism between dickkopf1 and dickkopf2 regulates Wnt/betacatenin signalling. Curr Biol 10, 1611-1614.

Wu, X., Tu, X., Joeng, K.S., Hilton, M.J., Williams, D.A., and Long, F. (2008). Rac1 activation controls nuclear localization of betacatenin during canonical Wnt signaling. Cell 133, 340-353.

Xu, Q., D'Amore, P.A., and Sokol, S.Y. (1998). Functional and biochemical interactions of Wnts with FrzA, a secreted Wnt antagonist. Development 125, 4767-4776.

Xu, Q., Wang, Y., Dabdoub, A., Smallwood, P.M., Williams, J., Woods, C., Kelley, M.W., Jiang, L., Tasman, W., Zhang, K., et al. (2004). Vascular development in the retina and inner ear: control by Norrin and Frizzled-4, a high-affinity ligand-receptor pair. Cell 116, 883-895.

Yamamoto, H., Sakane, H., Yamamoto, H., Michiue, T., and Kikuchi, A. (2008). Wnt3a and Dkk1 regulate distinct internalization pathways of LRP6 to tune the activation of beta-catenin signaling. Dev Cell 15, 37-48.

Zerlin, M., Julius, M.A., and Kitajewski, J. (2008). Wnt/Frizzled signaling in angiogenesis. Angiogenesis 11, 63-69.

Zhang, B., Abreu, J.G., Zhou, K., Chen, Y., Hu, Y., Zhou, T., He, X., and Ma, J.X. (2010a). Blocking the Wnt pathway, a unifying mechanism for an angiogenic inhibitor in the serine proteinase inhibitor family. Proc Natl Acad Sci U S A 107, 6900-6905.

Zhang, B., Hu, Y., and Ma, J.X. (2009). Anti-inflammatory and antioxidant effects of SERPINA3K in the retina. Invest Ophthalmol Vis Sci 50, 3943-3952.

Zhang, B., Ma, J.X., and Cookson, M.R. (2008). SERPINA3K prevents oxidative stress induced necrotic cell death by inhibiting calcium overload. PLoS ONE 3, e4077.

Zhang, B., Zhou, K.K., and Ma, J.X. (2010b). Inhibition of connective tissue growth factor overexpression in diabetic retinopathy by SERPINA3K via blocking the WNT/beta-catenin pathway. Diabetes 59, 1809-1816.

Zhang, X., Gaspard, J.P., and Chung, D.C. (2001). Regulation of vascular endothelial growth factor by the Wnt and K-ras pathways in colonic neoplasia. Cancer Res 61, 6050-6054. 